\title{
Utilização do Modelo HAND para mapeamento das áreas mais suscetíveis à inundação no Rio Uruguai
}

\author{
Vagner Paz MENGUE ${ }^{1}$, Fernando Comerlato SCOTTÁ ${ }^{2}$, Tatiana Silva da SILVA³ \& Flávia FARINA ${ }^{3}$ \\ 1 Programa de Pós-Graduação em Sensoriamento Remoto, Instituto de Geociências, Universidade Federal do Rio Grande do Sul. \\ Caixa Postal 15.074, CEP 91.501-970, Porto Alegre, RS, Brasil. E-mail: vagnergeo@yahoo.com.br. \\ 2 Programa de Pós-Graduação em Geociências, Instituto de Geociências, Universidade Federal do Rio Grande do Sul. Caixa Pos- \\ tal 15.001, CEP 91.509-900, Porto Alegre, RS, Brasil. E-mail: fernando.scotta@ufrgs.br. \\ 3 Departamento de Geodésia, Instituto de Geociências, Universidade Federal do Rio Grande do Sul. Caixa Postal 15.001, CEP \\ 91.509-900, Porto Alegre, RS, Brasil.E-mail: tatiana.silva@ufrgs.br, flavia.farina@ufrgs.br.
}

Recebido em 12/2014. Aceito para publicação em 01/2016. Versão online publicada em 23/02/2016 (www.pesquisasemgeociencias.ufrgs.br)

\begin{abstract}
Resumo - 0 objetivo do presente trabalho é apresentar uma aplicação do modelo HAND para mapeamento de áreas mais suscetíveis à inundação em uma área do Rio Uruguai e afluentes, próximo à cidade de Itaqui, Estado do Rio Grande do Sul, utilizando como base um evento de inundação ocorrido em 26/10/1997. Uma classificação de uma imagem LANDSAT 5, sensor TM, foi realizada visando gerar um mapa de referência com as áreas de inundação para comparar com as simulações do modelo HAND. A altura da inundação foi definida com base nos dados da cota da estação de Itaqui, localizada no Rio Uruguai, no dia analisado. As simulações pelo modelo HAND e o mapa de referência classificado pela imagem foram comparadas pela similaridade fuzzy, o índice de concordância Kappa e exatidão global. 0 valor de cota média diária da inundação, de 11,45 m, da estação de Itaqui foi fundamental para ajustar e avaliar a simulação de inundação gerada pelo modelo HAND. Tal valor de cota não é suficiente para inundar a área urbana do munícipio de Itaqui. Simulações de inundação de 15 m, 19 m e 23 m geradas com o modelo HAND apontam que as áreas oeste, norte e sul da cidade de Itaqui são mais suscetíveis à inundação. Considerando a disponibilidade gratuita dos dados e a obtenção rápida e satisfatória de resultados, essa metodologia pode ser empregada em outras regiões, podendo servir como uma ferramenta de planejamento e gestão em áreas de risco a inundações.
\end{abstract}

Palavras-chave: Sensoriamento Remoto, Itaqui, planejamento e gestão.

\begin{abstract}
USE THE HAND MODEL FOR MAPPING THE AREAS MORE SUSCEPTIBLE TO FLOODING IN THE Rio URUGUAI. THE AIM of this study was to use the HAND model to map areas more susceptible to flooding in an area of the Uruguai River and tributaries, near the Itaqui city, Rio Grande do Sul State, using as a base a flood event occurred on 10/26/1997. An image classification of a Landsat 5 , TM sensor, was carried out to generate a reference map with the flooded areas to compare with the HAND model simulations. The flood height was defined based on the data quota of Itaqui Station, located on the Uruguai River, on the day analyzed. Simulations by HAND model and the classified reference map were compared by fuzzy similarity, Kappa index and overall accuracy. The daily quota value of $11.45 \mathrm{~m}$, of Itaqui station in Uruguai River, was critical to adjust and evaluate the flood simulation generated by HAND model. Such cota value was not enough to flood the urban area of the Itaqui city. Flood simulations with $15 \mathrm{~m}, 19 \mathrm{~m}$ and $23 \mathrm{~m}$ yielded by the HAND model indicate that the west, north and south areas of Itaqui city are more susceptible to flood. Considering the free availability of data, and the fast and satisfactory availability of results, this methodology can be applied in other regions, and may serve as a tool for planning and management of areas at flood risk. Keywords: Remote Sensing, Itaqui, planning and management.
\end{abstract}

\section{Introdução}

Inundações destacam-se por ser provavelmente a catástrofe natural mais frequente e devastadora em todo o mundo (Sanyal \& Lu, 2004). Na última década do século $\mathrm{XX}$, estima-se que os even- tos de inundações foram responsáveis pela morte de cerca de 100 mil pessoas e que afetaram mais de 1,4 bilhão de pessoas (Jonkman, 2005).

Porém, os danos causados pelas inundações não se restringem à perda de vidas humanas. Estão documentados também prejuízos na infraes- 
trutura básica, nas atividades agrícolas (Lawal et al., 2011), no saneamento (Alsdorf et al., 2007) bem como impactos culturais e históricos (Jonkman, 2005). As inundações também afetam os ecossistemas terrestres. A deposição de sedimentos e a erosão do solo durante a inundação podem destruir áreas que previamente possuíam solos férteis para a agricultura (Alsdorf et al., 2007).

No Brasil, durante 1991-2010, as inundações foram responsáveis por afetar 40,19\% do total de 96.220.879 habitantes atingidos por desastres naturais. Este tipo de evento também foi o desastre natural com maior número total de mortos: entre as 2.475 pessoas mortas por desastres naturais, 1.456 mortes resultaram de eventos dessa natureza, representando 58,83 \% do total (UFSC, 2012).

Apesar disso, na maioria dos locais atingidos, há poucos investimentos, tanto em medidas estruturais, tais como obras de infraestrutura para amenizar os efeitos das inundações, quanto em medidas não estruturais, sejam mapeamentos de áreas de inundações, simulações e previsões hidrológica e meteorológica, e planejamento ocupacional de áreas de risco a inundações (Oliveira et al., 2011). Esta ausência de investimentos significativos em planejamento deixa a população vulnerável aos efeitos das inundações (Righi \& Robaina, 2012).

0 mapeamento de áreas suscetíveis à inundações pode amenizar ou até mesmo evitar os danos causados pelas inundações. Avanços no conhecimento de informática, sensoriamento remoto, sistemas de informação geográfica (SIG) e modelagem têm sido particularmente úteis na gestão de inundações (Schumann et al., 2009; Opolot, 2013). Por meio de técnicas de modelagem e análise espacial em SIG juntamente com dados oriundos de sensoriamento remoto as áreas de risco podem ser identificadas, mapeadas e analisadas (Opolot, 2013).

Os Modelos Digitais de Elevação (MDE) permitem descrever, compreender e prever o armazenamento e os movimentos da água na superfície terrestre (Moore et al., 1992). Tais modelos, quando inseridos em modelos hidrológicos permitem estimar a previsão do fluxo e da direção de escoamento da água e podem ser empregados como parâmetros para as políticas públicas para estabelecer planos de utilização para áreas com alta susceptibilidade a inundações.

0 modelo HAND (Height Above the Nearest Drainage ou Altura Acima da Drenagem Mais Próxima) desenvolvido por Rennó et al. (2008) é um dos modelos hidrológicos empregados na simulação de áreas mais suscetíveis à inundação. Esse modelo utiliza a diferença entre a altitude extraída do MDE e a rede de drenagem de referência para calcular alturas relativas, que possuem relação com a profundidade do lençol freático e com a topografia do terreno (Rennó et al., 2008; Nobre et al., 2011).

No contexto das recentes ocorrências de inundações no Estado do Rio Grande do Sul, os municípios localizados às margens do Rio Uruguai têm sido atingidos frequentemente por esses episódios. Entre os anos de 1980 a 2005 foram registrados 41 eventos nos municípios brasileiros que margeiam o Rio Uruguai (Righi \& Robaina, 2010). Apesar disso, diante de tantos prejuízos oriundos destes eventos, ainda há carência de estudos visando o mapeamento e a análise da ocorrência de inundações e seus efeitos nos municípios no baixo curso do Rio Uruguai (Righi \& Robaina, 2012).

Neste contexto, o objetivo desse trabalho é utilizar e avaliar o modelo HAND (M-HAND) para mapear áreas mais suscetíveis à inundação em uma área do Rio Uruguai e afluentes, próximo da cidade de Itaqui, considerando como base um evento de inundação ocorrido em 26/10/1997.

\section{2 Área, material e métodos}

\section{1 Área de estudo}

A área de estudo corresponde a uma seção do Rio Uruguai e afluentes, localizada entre as coordenadas de $29^{\circ} 07^{\prime} 31^{\prime \prime} \mathrm{S}$ e $56^{\circ} 33^{\prime} 11^{\prime \prime} \mathrm{W}$. Essa seção está situada na fronteira entre a Argentina e o Brasil, com a cidade de Itaqui localizada no território brasileiro, na margem esquerda do Rio Uruguai no Estado do Rio Grande do Sul. Na margem direita do rio, no território argentino, está situada a cidade de Alvear, pertencente à província de Corrientes (Fig. 1). Este trecho do rio foi escolhido por ser considerado uma zona de alto risco de inundação em frequência e impacto (ANA, 2014). Uma zona de alto risco é definida por apresentar cheias com frequência menor que cinco anos, impactos com risco de dano à vida humana e danos significativos a serviços essenciais, como instalações e obras de infraestrutura públicas e residências (Medeiros, 2011).

A população residente no município de Itaqui é de 38.159 habitantes (IBGE, 2014) e, em General Alvear, é de 7.926 habitantes (INDEC, 2010). Cultivos agrícolas de arroz irrigado, soja e milho são os principais usos do solo dessa área, com o Pampa sendo o bioma original (IBGE, 2014). O Rio Uruguai é o segundo sistema fluvial da bacia do Rio da Prata em importância, servindo de fronteira entre 
o Brasil e a Argentina. A seção analisada do rio está inserida na sub-bacia Hidrográfica do Ibicuí, que possui área de $35.495,38 \mathrm{~km}^{2}$ e população estimada em 394.030 habitantes (SEMA, 2014).

Segundo a classificação de IBGE (1986), a área localiza-se na unidade geomorfológica Planalto de Campanha, que apresenta relevo ondulado, com a altitude decaindo de forma gradativa em direção à calha do Rio Uruguai (Robaina et al., 2010). 0 clima é do tipo Cfa, apresentando precipitação pluvial bem distribuída (Reboita et al., 2010), cujos média anual é de 1613 para o período 1974-2004 (Viana et al., 2006). Devido a fortes eventos de precipitação pluvial, os municípios que margeiam o rio têm sido atingidos frequentemente por inundações.
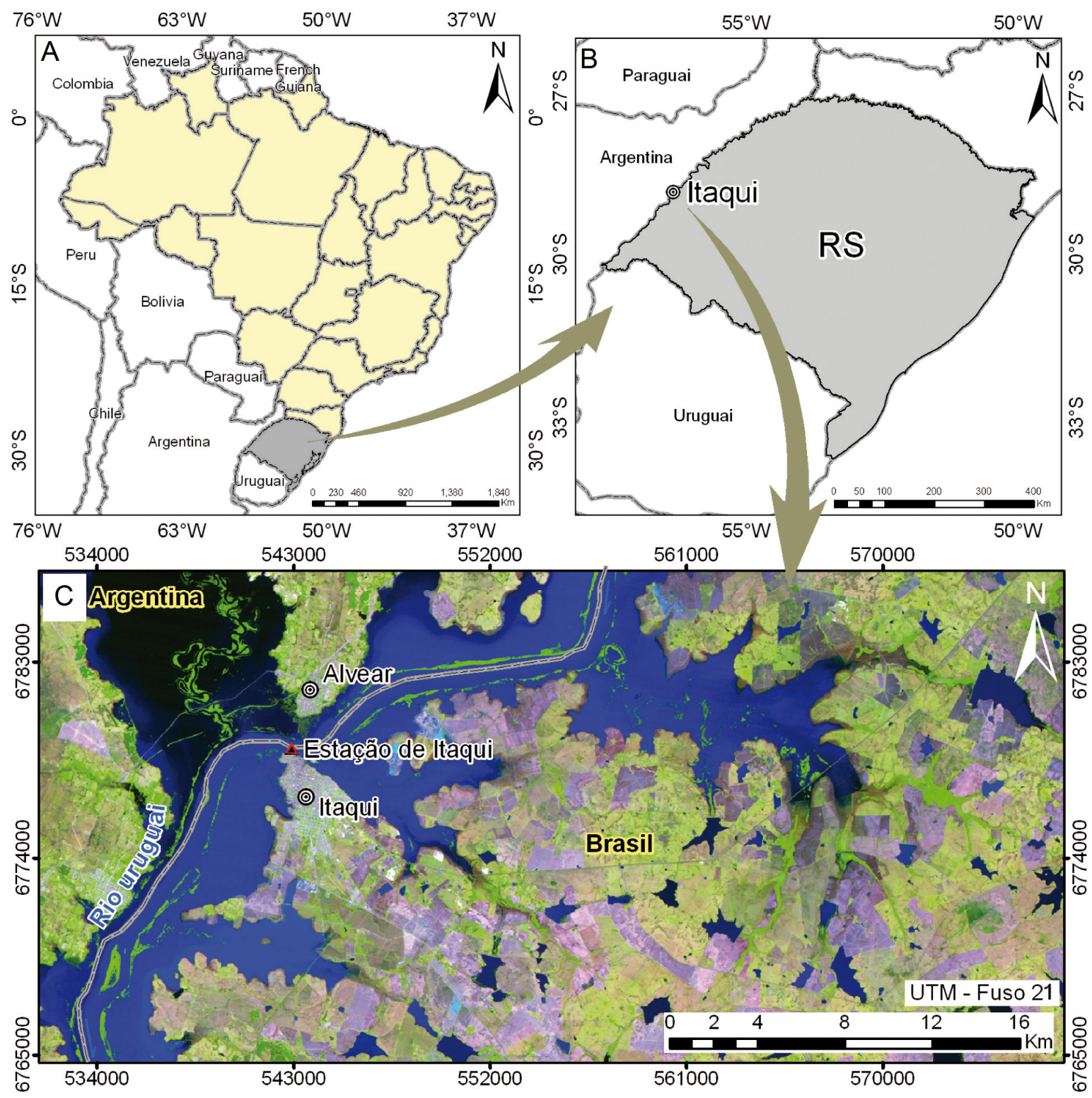

Figura 1. Localização da área de estudo. A) Localização do Estado do RS; B) Município de Itaqui; C) Área de estudo com uma composição colorida RGB 543, de 26/10/1997, LANDSAT 5 TM.

2.2 Definição do evento de inundação e aquisição dos dados

As etapas metodológicas do trabalho estão resumidas na figura 2 . 0 período do evento de inundação foi definido a partir do estudo proposto por Righi \& Robaina (2010), que registraram a ocorrência de inundações nos municípios atingidos ao longo do Rio Uruguai no período 1980-2005. Com base nesses registros para a cidade de Itaqui, buscou-se imagens de satélite correspondentes aos períodos que registraram os eventos de inundações na área. 0 produto selecionado no banco de dados do Instituto Nacional de Pesquisas Espaciais (INPE) corresponde a uma imagem do satélite Landsat 5, sensor Thematic Mapper (TM), com $30 \mathrm{~m}$ de resolução espacial, adquirida em 26/10/1997 (órbita 224, ponto 80). A inundação resultou de eventos de precipitação pluvial entre os dias 07 
a 16 de outubro de 1997, quando 11 municípios formalizaram situação de emergência, inclusive o município de Itaqui (Righi \& Robaina, 2012).

Os dados de cotas médias diárias do Rio Uruguai no mês de outubro foram obtidos na estação de Itaqui (Código 75900000; 29,12 S; 56,55 W; 43,82 m de altitude), a partir do endereço eletrô- nico (www.ana.gov.br) da Agência Nacional das Águas (ANA), servindo de referencial de inundação ao M-HAND. Dados SRTM (Shuttle Radar Topography Mission) foram adquiridos no endereço eletrônico www.earthexplorer.usgs.gov para servir de entrada no M-HAND, com resolução espacial de $90 \mathrm{~m}$.



Figura 2. Etapas metodológicas do trabalho.

\subsection{Georreferenciamento e classificação da imagem Landsat 5}

A imagem foi georreferenciada no sistema de referência UTM, zona 21S, com dados oriundos da imagem GLS-Landsat. Neste processo, utilizaram-se 30 pontos de controle, com erro médio quadrático de 0,71 pixels. Foi realizada uma classificação visando gerar um mapa de referência com as áreas de inundação para comparar com as simulações do M-HAND. Para tal, aplicou-se uma classificação supervisionada por máxima verossimilhança, utilizando as bandas TM4 e TM5, considerando-se o trabalho de Frazier \& Paige (2000), que apresentam uma metodologia de classificação de áreas alagadas com o sensor TM. A classificação supervisionada apresentou exatidão global de 96,5\% baseadas em amostras de verificação. Posteriormente, foi realizada uma classificação visual em tela, para detectar possíveis erros de classificação devido a imagem Landsat ter sido adquirida cinco dias após o pico de cheia, apresentando pequenas áreas isoladas com saturação da umidade do solo. Essas áreas, além de pequenos açudes, foram corrigidas através da classificação visual em tela. A última etapa foi reamostrar para $90 \mathrm{~m}$ o mapa de referência com o objetivo de comparar com a resolução espacial do modelo HAND.

\subsection{Processamento do modelo HAND}

A identificação da área de inundação teve por base o emprego do M-HAND, inserido no software livre Terra Hidro, desenvolvido pelo INPE. Este modelo possibilita a geração de simulações de cotas de inundações através de dados topográficos em formato matricial, como MDE, resultando no mapeamento das áreas mais suscetíveis à inundação, fundamentando-se na distância vertical à drenagem mais próxima. Nobre et al. (2011) e Rennó et al. (2008) explicam que a partir da rede de drenagem extraída do dado topográfico, a diferença entre cada elemento da grade MDE e o ponto mais próximo associado à rede de drenagem extraída dá origem ao modelo de superfície HAND, portanto o nível de referência deixa de ser fixo em relação ao mar e passa a ser relativo à rede de drenagem mais próxima. Na figura 3 é possível observar que o atributo de altitude de um determinado ponto é definido pela posição que este se encontra em relação ao curso d'água para o qual ele deságua, iniciando uma contagem a partir do zero e aumentando o valor na medida em que se distância da drenagem.

A partir do MDE são calculadas as direções de fluxo e as áreas acumuladas de drenagem (Rodrigues et al., 2011), sendo o SRTM escolhido como o modelo de entrada. Neste trabalho foram testados 


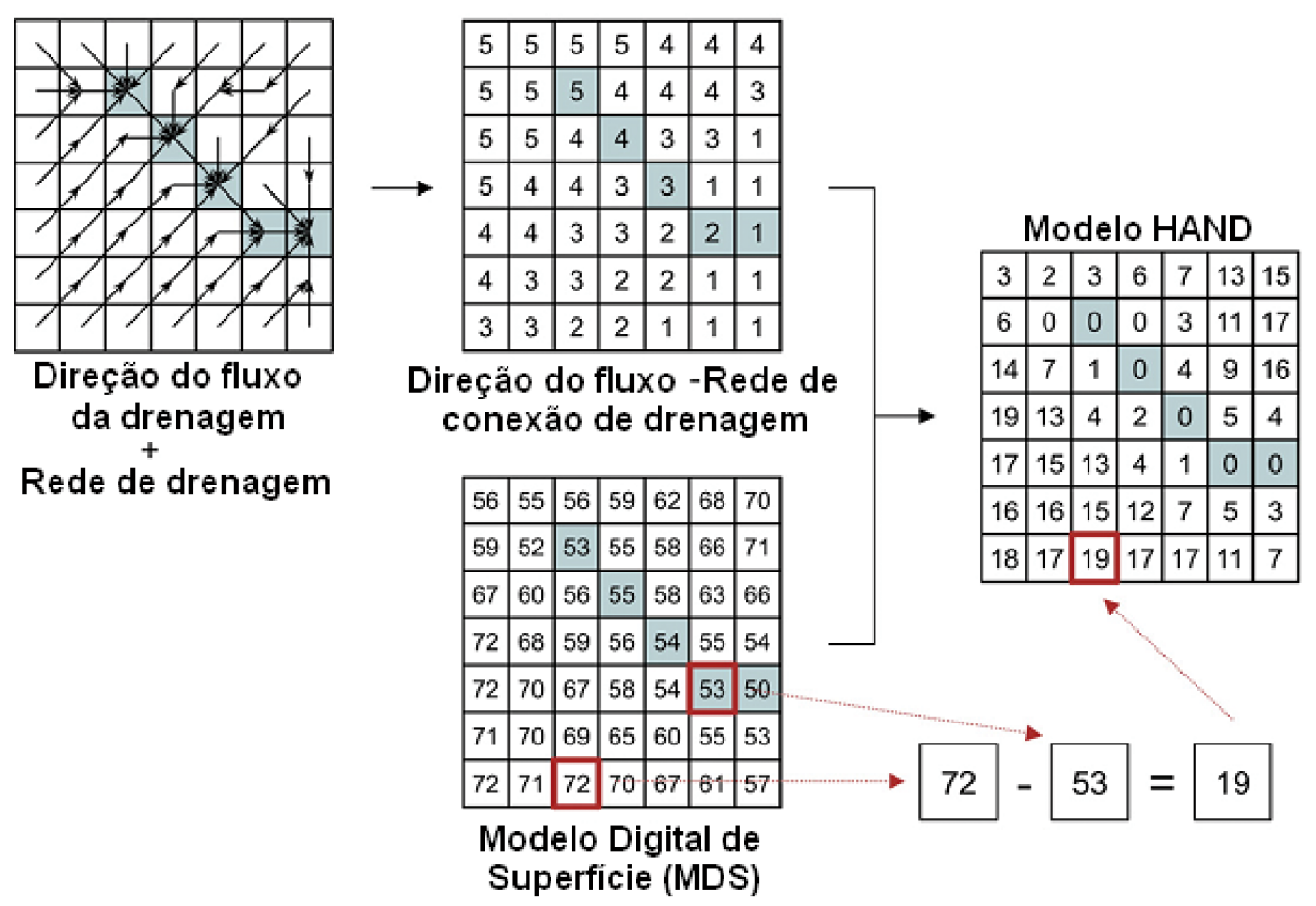

Figura 3. Esquema de cálculo do modelo Hand: os quadrados marcados representam os pontos da grade que pertencem à rede de drenagem; somente as setas pretas são consideradas como direção de fluxo das drenagens (adaptado de Rennó et al., 2008).

dois métodos de pré-processamento para a geração do M-HAND. 0 método 01 possui procedimentos automáticos que determinam as direções de fluxo e as áreas acumuladas de drenagem no MDE, com correções topológicas definidas por Rennó et al. (2008). Em síntese, é definido para qual dos pixels vizinhos um determinado pixel drena a água em superfície (direção de fluxo) e a área de drenagem que contribui para cada pixel (área acumulada), originando a rede de drenagem.

0 método 02 baseia-se na correção do MDE por afundamento (Fig. 4), sugerido por Silva et al. (2013). Nesse método é utilizada uma hidrografia vetorial de referência na escala 1:100.000, disponibilizada pela Agência Nacional de Águas (ANA), onde são corrigidas as depressões (filling a sink) presentes no MDE, conforme proposto por Araújo Júnior et al. (2011). 0 MDE é afundado pela drenagem vetorial, sendo realizada uma subtração (nesse trabalho foi utilizado $10 \mathrm{~m}$ ) nos pixels onde a drenagem percorre. Na etapa seguinte de pré-processamento, são geradas a direção de fluxo modificada pelo afundamento e a área acumulada. 0 resultado deste procedimento é a obtenção de uma hidrografia sintética de referência. É importante ressaltar que a geração do M-HAND utilizou o MDE original (sem afundamento), direção de fluxo afundada e a hidrografia sintética, desta maneira é assegurada a distância vertical correta, oriunda do MDE original (sem afundamento). Porém, a origem para a altura zero do M-HAND foi certificada pelos pixels do traçado "correto" da drenagem vetorial da carta 1:100.000.

Foram testados quatro limiares (threshold) como parâmetros para geração da rede de drenagem: 600, 2000, 5000 e 10000 (Fig. 2). Assim, o M-HAND foi processado oito vezes, sendo cada limiar processado duas vezes, com e sem afundamento. O limiar representa áreas acumuladas da drenagem, sendo este um parâmetro definido pelo usuário. Os valores do limiar são uma contagem do número de pixels cujos fluxos da drenagem convergem para um pixel considerado. Seu valor modifica alguns parâmetros, como a densidade de drenagem da área de estudo. Para os oito processamentos, a cota de inundação foi definida com base nos dados fornecidos pela estação de Itaqui no dia 26/10/1997, com valor médio de $11,45 \mathrm{~m}$, a partir de duas leituras realizadas as $7 \mathrm{~h}$ e $17 \mathrm{~h}$, com valores de 11,57 e 11,33 $\mathrm{m}$, respectivamente.

As simulações para mapear as áreas mais suscetíveis à inundação, enfocando a área urbana de Itaqui, foram geradas utilizando-se as cotas de 15 $\mathrm{m}, 19 \mathrm{~m}$ e $23 \mathrm{~m}$. 




Figura 4. Esquema de cálculo do afundamento do MDE (neste trabalho foi realizado um afundamento de $10 \mathrm{~m}$ ).

\subsection{Comparação do modelo HAND com o mapa de referência}

Para validar os resultados da área do mapa de referência de inundação elaborado a partir da imagem e da área de inundação gerada a partir do M-HAND, foram realizadas análises de similaridade fuzzy, obtenção do índice de concordância Kappa (IK) e da exatidão global (EG). 0 método de validação pelo índice de similaridade fuzzy, proposto por Hagen (2003), utiliza como dados de entrada um mapa de referência (classificação pela imagem Landsat 5) e os dados da classificação da área de inundação gerada pelo M-HAND. 0 índice varia de 0 a 1 , onde valores próximos a 0 indicam similaridade baixa e valores próximos a 1 indicam similaridade alta entre os mapas. Foi empregado o método de função de decaimento constante com janelas de tamanhos que variaram de $1 \times 1$ a $11 \times 11$ pixels.

0 índice de exatidão global e o índice de concordância Kappa foram calculados com o uso de 400 amostras (400 pontos), das quais metade foi obtida aleatoriamente, sobre o alvo de interesse (máscara de inundação gerada pelo M- HAND), e a outra metade foi sorteada aleatoriamente fora das áreas de inundação gerada pelo M-HAND. Desta maneira, procurou-se evitar que os erros de inclusão e omissão fossem mascarados na análise. Este processo foi repetido para todos os parâmetros de limiares (threshold) testados na geração da rede de drenagem, isto é, oito vezes no total.

\section{Resultados e discussão}

Através da elaboração das máscaras geradas pelo M-HAND, foi possível identificar e separar as áreas suscetíveis à inundação. Segundo dados da estação de Itaqui, o Rio Uruguai atingiu a altura máxima do mês no dia 21/10/1997, registrando 13,29 $\mathrm{m}$, inundando inclusive a área urbana do município. A imagem Landsat TM 5 empregada para validar os resultados é do dia 26/10/1997, isto é, cinco dias após o nível máximo registrado no rio. 0 valor médio registrado no dia 26/10 é de 11,45 m (Fig. 5).

A partir da análise visual do cruzamento entre a hidrografia vetorial e a hidrografia extraída com base na direção de fluxo do MDE das imagens SRTM, conclui-se que as drenagens no Rio Uruguai são semelhantes para os dois métodos. As maiores diferenças espaciais entre as duas hidrografias ocorreram nas drenagens que confluem para o Rio Uruguai, na porção noroeste da área de estudo, onde existe uma grande zona de várzea, com baixa declividade (Fig.6). Tais discrepâncias estão associados a imprecisões relativas no valor altimétrico dos dados SRTM e da própria resolução espacial (90 m), omitindo informações importantes do relevo. 


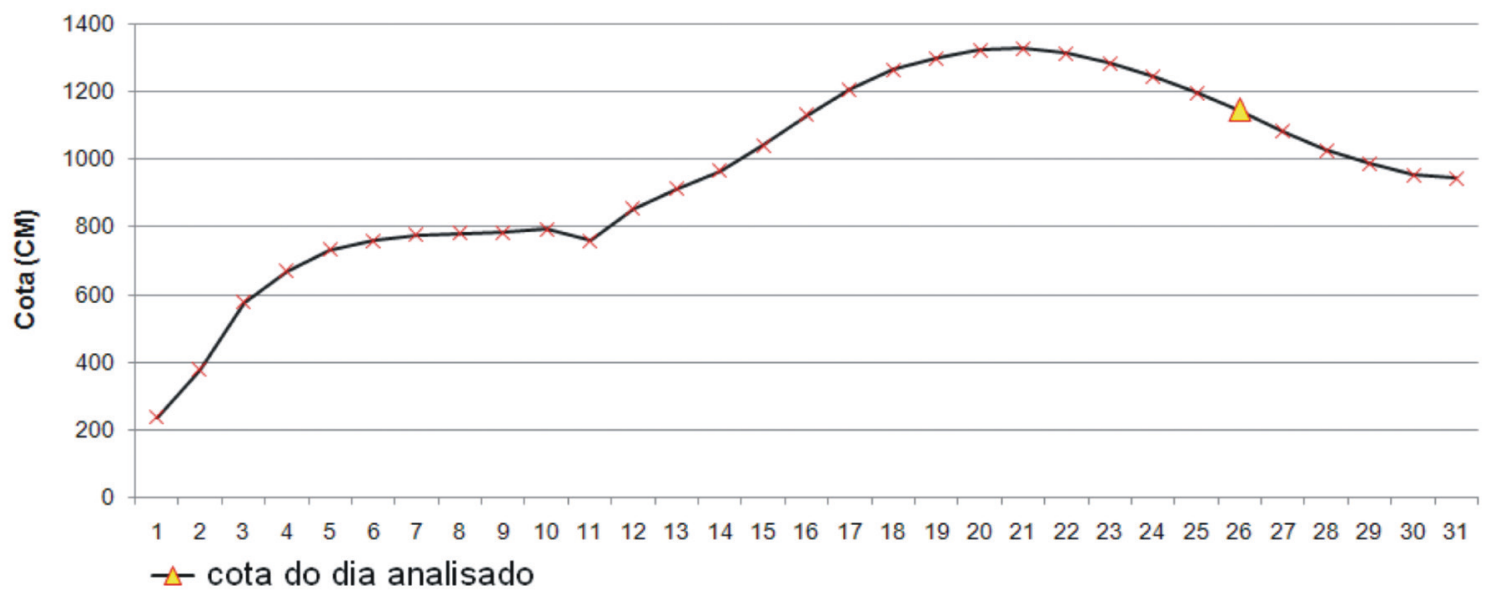

Dias

Figura 5. Gráfico de cotas médias diárias para a estação de Itaqui, 10/1997 (Fonte: ANA, 2014).

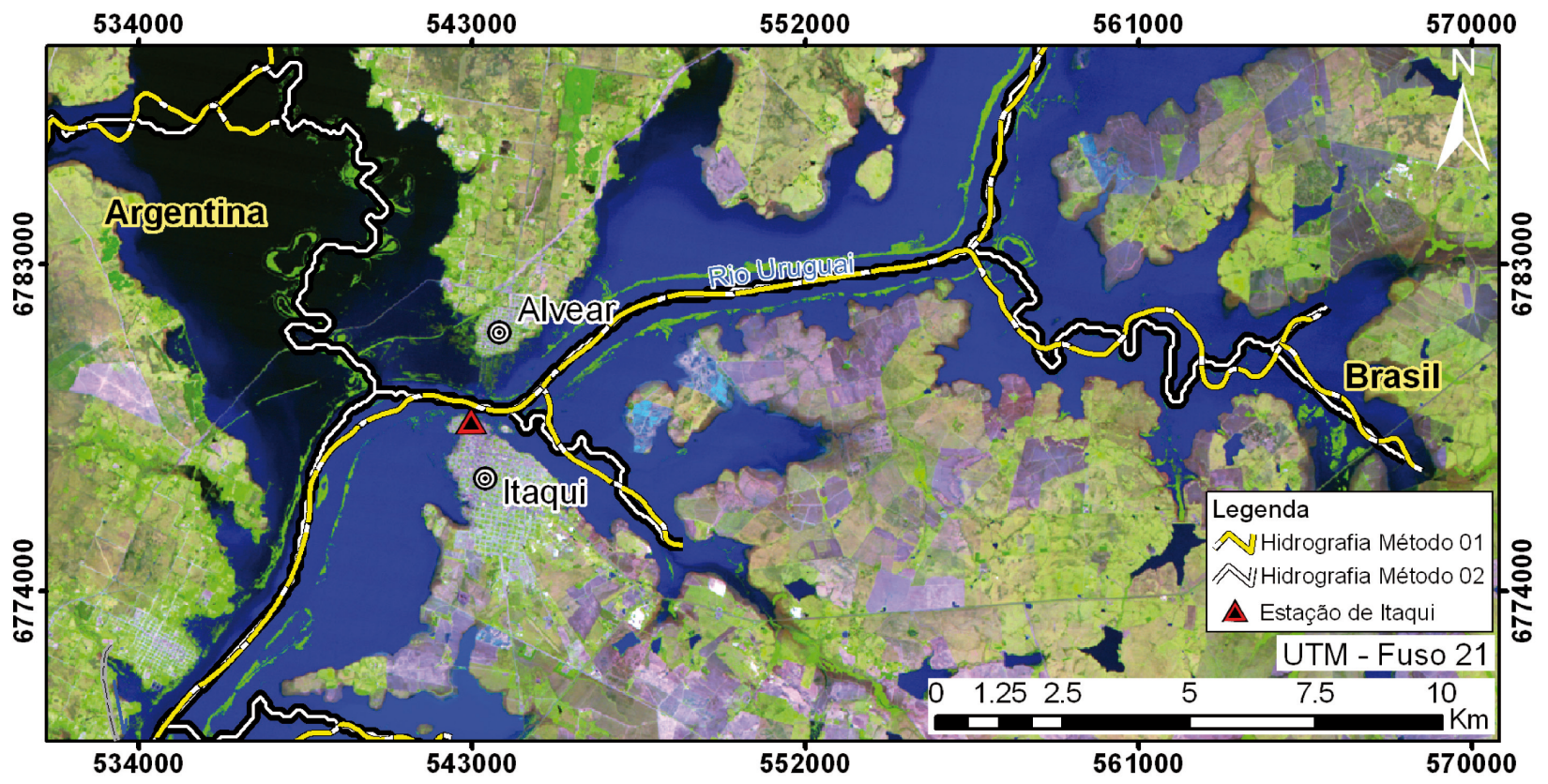

Figura 6. Comparação entre hidrografias com limiar de 10000 para os dois métodos analisados. Composição da imagem Landsat 5 TM RGB 245.

Os melhores dados de concordância espacial entre os dados simulados e o mapa de referência localizam-se nas áreas próximas da estação de Itaqui, onde o contorno da área de inundação é melhor definido, principalmente próximo à área urbana. Nas áreas mais distantes da estação e principalmente nas áreas de drenagem de maior altitude, as maiores discrepâncias foram registradas (Fig. 7). Os resultados da aplicação do M-HAND com diferentes limiares são visualmente semelhantes em algumas áreas, porém são registradas maiores diferenças nas zonas onde o desnível do terreno é muito baixo (Fig. 7). No oeste da região analisada, registraram-se elevadas diferenças entre os limiares em áreas planas.

Comparando-se os resultados das simulações geradas pelo M-HAND com o mapa de referência gerado a partir da imagem Landsat TM 5, os maiores valores de similaridade fuzzy encontrados foram para o limiar 10000 (Fig. 8). 0 valor mínimo foi de 0,6086 (janela $1 \times 1$ para método 02 ) e o máximo de 0,6952 (janela 11x11 para método 01). Diversos trabalhos (Almeida et al., 2008; Xaud et al., 2009; Barni, 2009; Soares-filho et al., 2013; Macedo et al., 2013; Santos et al., 2014) consideraram que os valores oscilando entre 0.45 a 0.50 para janelas de amostragem com tamanhos de $3 \times 3$ a $5 \times 5$ são concordâncias aceitáveis entre o mapa simulado e o mapa de referência. É possível perceber que a partir da janela de amostragem $7 \times 7$ o índice praticamente se estabiliza. Conforme Ferrari (2008), o índice tende a aumentar quanto maior forem as 
janelas de amostragem; desta maneira, a partir de certa janela (em geral, acima de $11 \times 11$ ou 13x13) é comum ocorrer saturação, conferindo ineficiência do índice para avaliar a concordância entre o mapa simulado e o mapa de referência.

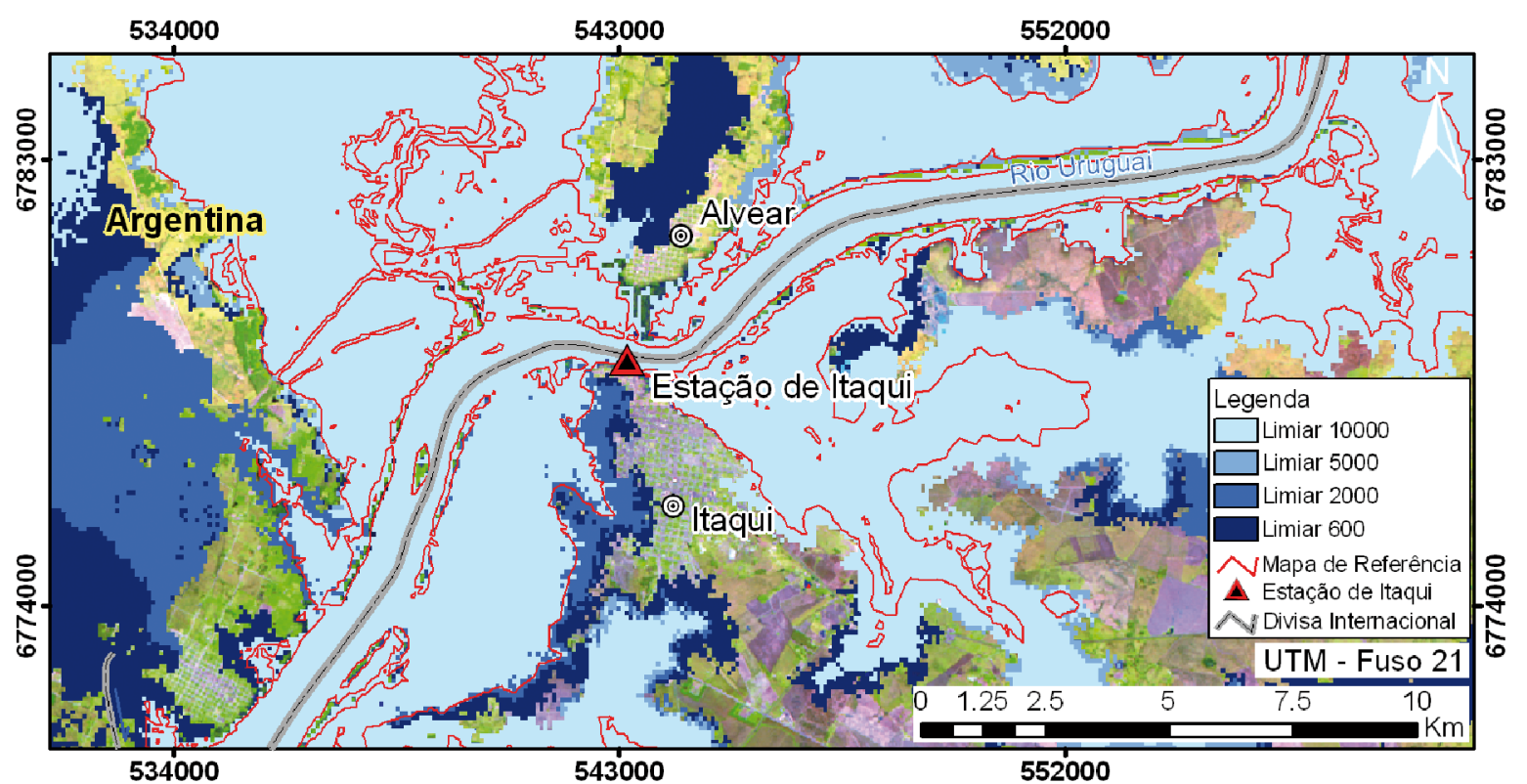

Figura 7. Resultados do mapeamento das áreas de inundação com os M-HAND com diferentes limiares (threshold), método 01.



Figura 8. Gráfico da similaridade fuzzy, entre o mapa de referência e os mapas das áreas de inundação estimados pelo M-HAND, Método 01 (S) e Método 02 (C).

Os valores similaridade fuzzy do método 01 foram maiores que o método 02 nas cinco janelas, para todos os limiares (Fig. 8), mostrando que o método sem afundamento da drenagem apresentou os melhores resultados. Silva et al. (2013) ao testar a imposição do trajeto dos rios pelo afundamento com uma hidrografia de referência para gerar o M-HAND, concluiram que está técnica foi essencial para a correta indicação das áreas suscetíveis à inundação. No entanto, nesse trabalho o afundamento da drenagem (método 02) não me- lhorou a qualidade da predição de inundação do M-HAND (Fig. 7). Uma possível explicação para a discordância dos resultados está na diferença das declividades das áreas analisadas, que é maior no trabalho de Silva et al. (2013) do que no Rio Uruguai.

Com relação à exatidão global, o limiar 10000 do método 1 foi o único a apresentar valores acima de $80 \%$, considerado aceitável por ESRI (1994). Para o índice Kappa, o método 01 variou entre 0,43 a 0,62 e para o método 02 entre 0,44 a 0,54 (Tab. 
01), o que, segundo classificação proposta por Landis \& Kock (1977), corresponde a bom a muito bom. 0 maior valor do índice Kappa também ocorreu com o limiar 10000 do método 1 .

Tabela 1. Exatidão Global e Kappa para os diferentes limiares.

\begin{tabular}{ccccc}
\hline & \multicolumn{2}{c}{ Método 1 } & \multicolumn{2}{c}{ Método 2 } \\
\hline $\begin{array}{c}\text { Limiar } \\
\text { (threshold })\end{array}$ & $\begin{array}{c}\text { Exatidão } \\
\text { Global }\end{array}$ & Kappa & $\begin{array}{c}\text { Exatidão } \\
\text { Global }\end{array}$ & Kappa \\
\hline 600 & $71,50 \%$ & 0,43 & $72,00 \%$ & 0,44 \\
\hline 2000 & $75,00 \%$ & 0,50 & $75,75 \%$ & 0,51 \\
\hline 5000 & $79,50 \%$ & 0,59 & $76,75 \%$ & 0,53 \\
\hline 10000 & $81,00 \%$ & 0,62 & $77,00 \%$ & 0,54 \\
\hline
\end{tabular}

Townsend (2001) empregou imagens RADARSAT obtidas entre os anos de 1996 e 1998 para identificar áreas de inundação nas florestas no Rio Roanoke, Carolina do Norte, EUA. Para determinar a área de inundação, o autor aplicou nas imagens de radar classificações por árvore de decisão, comparando os resultados com 13 estações do USGS (United States Geological Survey), distribuídas ao longo da planície de inundação daquele rio. O EG médio resultou em 93,5\%, concluindo-se que as imagens RADARSAT são eficazes e apropriadas para o mapeamento da planície de inundação em florestas, independente da época ou do nível da água. Martinez \& Toan (2006) encontraram IK médio de 0,82 para mapear a dinâmica temporal da planície de inundação e da distribuição espacial da vegetação em um trecho de várzea do Rio Amazonas. Os referidos autores fizeram uso de séries temporais de imagens de radar do J-ERS e comparam os resultados com imagens Landsat-5 TM, dados batimétricos e fotografias aéreas.

Os resultados obtidos neste trabalho apresentaram menor acurácia quando comparados a outros trabalhos do gênero, porém cabe ressaltar que os dados utilizados são de menor resolução espacial ( $90 \mathrm{~m}$ ) e a geração da máscara de inundação se deu de forma sistemática. Por outro lado, o rápido processamento e o baixo custo de operação tornam esta metodologia promissora e aplicável em diversas escalas, já que a qualidade do modelo depende da resolução espacial do dado de entrada, ou seja, da qualidade do MDE utilizado. Quanto menor o tamanho do pixel, mais precisos e fidedignos serão os dados do M-HAND (Nobre et al., 2011). 0 fato da área de estudo estar situada numa região com relevo suavemente ondulado não restringe a utilização do M-HAND combinado com o auxílio de imagens de satélite para mapear áreas suscetíveis à inundação em outras regiões com características distintas.

Analisando os índices de similaridade fuzzy,
Kappa e exatidão global, observa-se que os valores aumentam com o aumento do limiar. Limiares menores apresentaram uma rede de drenagem muito densa e incompatível com a escala de análise. Por outro lado, a rede de drenagem gerada com limiares de 10000 apresentaram uma densidade de drenagem menor e mais apropriada para a escala, compatível com a hidrografia da ANA em escala 1:100.000.

A simulação gerada com o M-HAND com o método 01 e limiar de 10000 apresentou os melhores resultados pelos índices de similaridade fuzzy, Kappa e exatidão global. É importante destacar que a espacialização das áreas de inundação considerou o modelo de elevação normalizada com a drenagem mais próxima, desta forma o objetivo principal é mostrar o desnível existente na lâmina d'água com relação à hidrografia existente na região.

A figura 9 destaca a área de inundação com a primeira cota simulada de $11,45 \mathrm{~m}$ (primeiro método e limiar de 10000), dado oriundo da estação de Itaqui do dia 26/10/97. A delimitação da inundação em torno da estação apresenta uma alta exatidão espacial, comprovada por meio dos testes estatísticos aplicados. As simulações de inundação realizadas (também com método 01 e limiar de 10000 ) de 15, 19 e 23 m permitiram observar as áreas mais suscetíveis à inundação no perímetro urbano de Itaqui. De acordo com o mapa, as regiões ao norte e oeste apresentam maior vulnerabilidade à inundações, com cotas de 11,45 m sendo suficientes para começar a inundar. Através dos perfis topográficos traçados nos planos norte-sul e leste-oeste, é possível visualizar que estas regiões estão num patamar mais baixo e com um relevo mais suave, principalmente na parte oeste da cidade.

Saueressig (2012) trabalhou com o zoneamento à inundação do perímetro urbano de Itaqui e conclui que a partir da cota fluviométrica de 10 $\mathrm{m}$ as cheias começam a atingir as zonas urbanizadas, especialmente os bairros localizados nas regiões ribeirinhas. Observa-se que os resultados do M-HAND são similares aos de Saueressig (2012) na definição das áreas mais suscetíveis à inundação. Nos registros da estação de Itaqui entre 19802010, a maior inundação registrada foi de 14,52 m no ano de 1983 (Saueressig, 2012). Os resultados do M-HAND são semelhantes para a simulação de $15 \mathrm{~m}$, com as áreas norte e oeste do perímetro urbano sendo mais afetadas em virtude da menor altitude do terreno (Fig. 9).

A simulação de inundação aos $23 \mathrm{~m}$ mostra que $63,97 \%$ do perímetro urbano ficaria inundada. A porção nordeste do perímetro urbano, próxi- 
ma ao Arroio Cambai, não foi atingida pela simulação de inundação em razão de estar situada em um patamar mais elevado do terreno. No entanto, o setor central do perímetro urbano foi atingido pela inundação mesmo distante das drenagens, o que pode ser explicado pela baixa altura em relação à drenagem mais próxima. Fica evidente que a utilização das distâncias verticais da drenagem gerada pelo M-HAND, em vez de apenas as distâncias horizontais, devem ser adotadas para delimitação de áreas suscetíveis à inundação, tanto em locais urbanos como em locais rurais.

É importante destacar que a cota de inundação não se elevará linearmente ao longo da drenagem, embora tenha sido adotado um valor único de cota inundação, atrelado ao ponto da estação. Dessa forma, a exatidão do M-HAND é maior mais próximo da estação e as maiores discrepâncias ocorrerão em áreas mais distantes (Fig. 7), sendo este método limitado espacialmente as áreas com estações com dados de cota de inundação.

Cabe destacar que os dados SRTM possuem algumas características indesejáveis do ponto de vista da modelagem topográfica (Valeriano \& Abdon, 2007). Esses dados são sensíveis a quaisquer objetos presentes na superfície do terreno, tais como antenas, edificações e mesmo variações da cobertura vegetal, dificultando a percepção somente da superfície do terreno. Dessa forma, as simulações realizadas no ambiente urbano possuem limitações visto que o MDE não representa a superfície do terreno, incluindo também as altitudes de topo das construções urbanas, aumentando os valores reais. Em razão disso, a simulação apresentada no município de Itaqui apresenta falhas devido a superfície do terreno não ser corretamente representada. Apesar disso, as simulações apresentam semelhanças espaciais com os resultados de Saueressig (2012). Um outro exemplo de interferência do SRTM pode ser observado nas áreas de mata ciliar no Rio Uruguai (Fig. 7 e 9), que na aplicação do M-HAND não foram inundadas em virtude dos dados SRTM registrarem a altitude do topo das árvores e não a superfície do terreno onde se localizam.

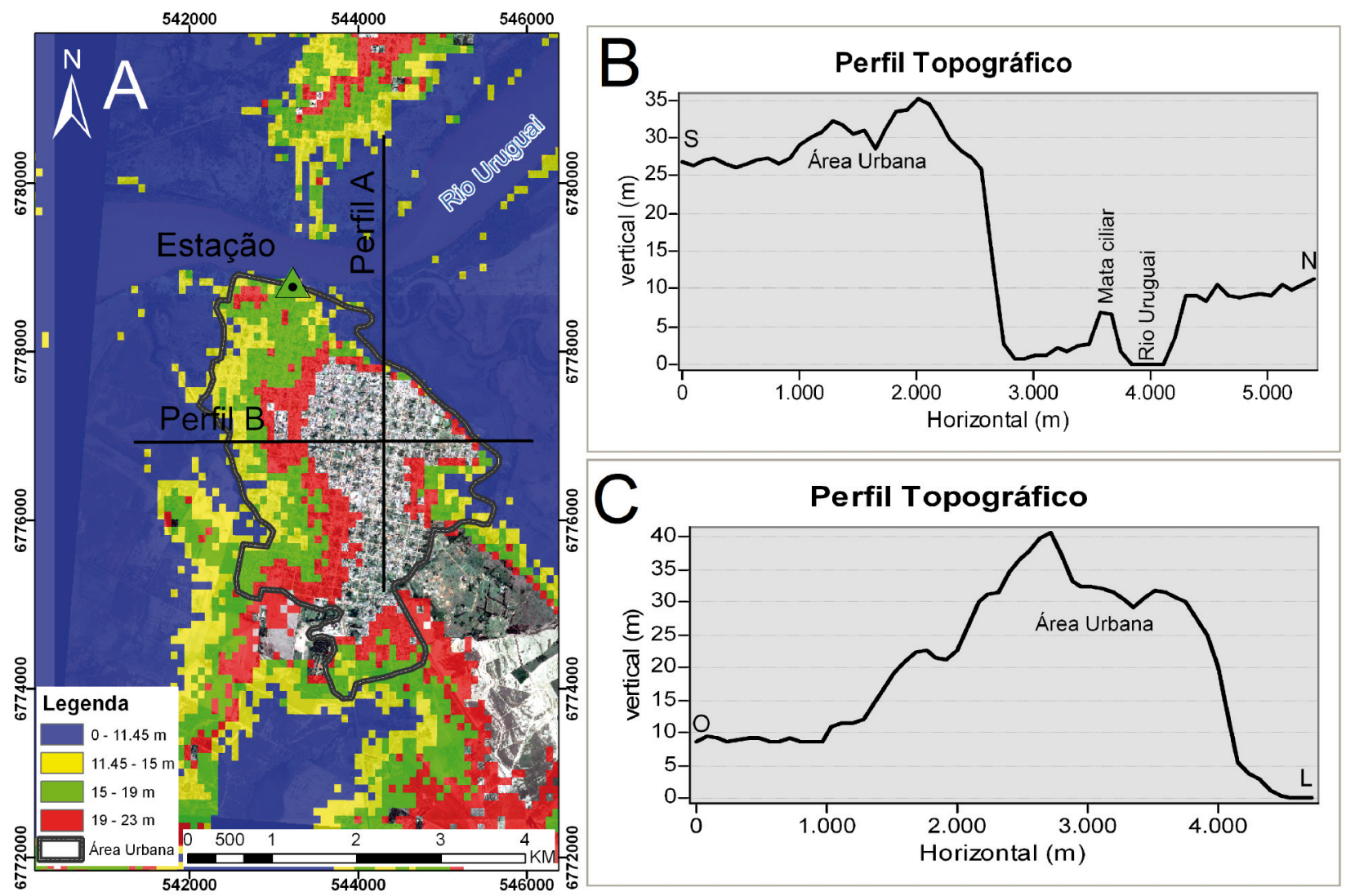

Figura 9. Perfil topográfico do perímetro urbano de Itaqui com as simulações das cotas de inundações. A) Localização dos perfis topográficos; B) Perfil topográfico N-S; C) Perfil topográfico O-L. 


\section{Conclusões}

O uso do M-HAND demonstrou ser adequado para mapear o evento de inundação ocorrido no mês de outubro de 1997. O uso da cota diária da estação de Itaqui no Rio Uruguai permitiu ajustar e avaliar a simulação de inundação gerada pelo M-HAND, sendo um parâmetro de referência fundamental para o resultado encontrado. A diferença no horário da aquisição da imagem (10h10min) e da leitura média da cota (valores coletados as $7 \mathrm{e}$ $17 \mathrm{~h}$ ) não foi avaliada, porém a pequena diferença de magnitude dos dados de cota provavelmente não modificou o resultado de forma significativa.

0 uso da imagem de 26/10/1997 possibilitou a comparação entre a área inundada do Rio Uruguai e a área que o M-HAND estimou como inundada. Através dessa comparação, foi possível determinar o limiar mais adequado para o modelo se ajustar à área inundada real. É relevante mencionar que o dado de cota do rio e a imagem empregada foram obtidos de fontes sem custos, com fácil acesso e constituem-se em informação que pode ser aplicada rapidamente para o ajuste do M-HAND. Em comparação ao trabalho de Silva et al. (2013), o método aqui empregado indicou que $o$ afundamento do MDE pela drenagem vetorial fornecida pela ANA (método 02) não melhorou a qualidade da predição de inundação do M-HAND.

Os resultados obtidos nesse estudo contribuíram para mapeamento das áreas de risco de inundação no município de Itaqui, podendo servir de base para as políticas públicas de planejamento e gestão da ocupação dessa área. Observou-se que as áreas norte e oeste da cidade de Itaqui são as mais suscetíveis à inundação, concordando com os resultados de Saueressig (2012).

Recomenda-se a utilização de Modelos Digitais do Terreno, ao invés de Modelos Digitais de Superfície, visto que dados topográficos, como o SRTM, coletam informação de toda a superfície do terreno, como edificações e cobertura vegetal, comprometendo os dados do M-HAND para simulações, principalmente em áreas urbanas e ao longo de cursos d'água com vegetação arbórea.

Pela disponibilidade gratuita dos dados e aplicabilidade rápida e satisfatória, essa metodologia pode ser empregada em outras regiões, respeitando-se as especificidades locais. Neste sentido, dados topográficos com resolução espacial maior poderão gerar simulações mais precisas das áreas suscetíveis à inundação.

\section{Referências}

Almeida, C.M., Gleriani, J.M., Castejon, E.F. \& Soares-Filho, B. S. 2008. Using neural networks and cellular automata for modeling intra-urban land use dynamics. International Journal of Geographical Information Science, 22(9): 943-963.

Alsdorf, D.E., Rodriguez, E. \& Lettenmaier, D.P. 2007. Measuring surface water from space. $R e$ views of Geophysics, 5:1-24.

ANA. Agência Nacional de Águas. 2014. Mapa de vulnerabilidade a inundações - Brasil. Disponível em: <http://www2.snirh.gov.br/home/ webmap/viewer.html?webmap $=$ cf201bd9b2c 540fa951b0619006eb2af>. Acesso em: 31 jul. 2014.

Araújo Júnior, G.J.L.D., Pinto, M.B.P., Trigo, A.J., Prado, A., Teixeira, A.A., Ferreira, F.V., Borelli, A.J., Silva, M.A., Scherer-Warren, M. \& Godinho, J.M. 2011. Metodologia de delimitação de áreas de drenagem por trecho de curso d'água coincidente com a cartografia em diferentes escalas utilizando modelo digital de elevação. In: SIMPÓSIO BRASILEIRO DE SENSORIAMENTO REMOTO, 15, 2011, Curitiba. Anais... São José dos Campos, INPE, 2011, v. 1, p. 1256-1262.

Barni, P. E. 2009. Reconstrução e asfaltamento da Rodovia BR-319: Efeito "dominó" pode elevar as taxas de desmatamento no Sul do Estado de Roraima. Manaus, 136 p. Dissertação de Mestrado, Programa de Pós-graduação em Ciências de Florestas Tropicais, Universidade Federal da Amazônia.

ESRI. Environmental Systems Research Institute. 1994. Accuracy assessment procedures e final draft. Redlands, Environmental Systems Research Institute, Santa Barbara, National Center for Geographic Informationand Analysis, The Nature Conservancy, 115 p.

Ferrari, R. 2008. Modelagem dinâmica do uso e cobertura da terra da Quarta Colônia, RS. Santa Maria, 130f. Dissertação de Mestrado, Programa de Pós-Graduação em Geomática, Universidade Federal de Santa Maria.

Frazier, P.S. \& Page, K.J. 2000. Water body detection and delineation with Landsat TM data. Photogrammetric Engineering \& Remote Sensing, 66(12): 1461-1467.

Hagen, A. 2003. Fuzzy set approach to assessing similarity of categorical maps. International Journal of Geographical Information Science, 17(3): 235-249.

IBGE. Instituto Brasileiro de Geografia e Estatística. 1986. Levantamento dos recursos naturais: folha SH.22 Porto Alegre e parte das folhas SH.21 
Uruguaiana e SI.22 Lagoa Mirim. Rio de Janeiro, IBGE, vol. 33.

IBGE. Instituto Brasileiro de Geografia e Estatística. 2014. IBGE Cidades. Disponível em: <http://www.ibge.com.br/cidadesat/xtras/ home.php>. Acesso em: 07 abr. 2014.

INDEC. Instituto Nacional de Estadística y Censos. 2010. Censo Agropecuário 2010. Disponível em: http://www.sig.indec.gov.ar/censo2010/>. Acesso em: 07 abr. 2014.

Jonkman, S.N. 2005. Global perspectives on loss of human life caused by floods. Natural Hazards, 34: 151-175.

Landis, J.R. \& Koch, G.G. 1977. The measurement of observer agreement for categorical data. Biometrics, 33: 159-174.

Lawal, D.U., Matori, A., Hashim, A.M., Chandio, I.A., Sabri, S., Balogun, A. \& Abba, H.A. 2011. Geographic information system and remote sensing applications in flood hazards management: A Review. Research Journal of Applied Sciences, Engineering and Technology, 3(9): 933-947.

Macedo, R.C., Almeida, C.M., Santos, J.R. \& Rudorff, B.F.T. 2013. Modelagem dinâmica espacial das alterações de cobertura e uso do solo da terra relacionados à expansão canavieira. Boletim de Ciências Geodésicas, 19(2): 313-337.

Martinez, J.M. \& Toan, T.L. 2006. Mapping of flood dynamics and spatial distribution of vegetation in the Amazon flood plain using multi temporal SAR data. Remote Sensing of Environment, 108: 209-223.

Medeiros, M.J. 2011. Diagnóstico da ocorrência de inundações no Brasil como ferramenta de planejamento: o atlas de vulnerabilidade a inundações. In: SIMPÓSIO BRASILEIRO DE RECURSOS HÍDRICOS, 19, 2011, Maceió. Anais..., Maceió. ABRH, v. 1, p. 1-11.

Moore, I., Grayson, R. \& Ladson, A. 1992. Digital terrain modeling: a review of hydrological, geomorphological, and biological applications. Hydrological Processes, 5(1): 3-30.

Nobre, A., Cuartas, L.A., Hodnett, M., Rennó, C.D., Rodrigues, G., Silveira, A., Waterloo, M. \& Saleska, S. 2011. Height Above the Nearest Drainage - a hydrologically relevant new terrain model. Journal of Hydrology, 404: 13-29.

Oliveira, G., Saldanha, D. \& Guasselli, L.A. 2011. Modelos para a espacialização e previsão de áreas inundáveis na zona urbana de São Sebastião do Caí, RS, Brasil. Pesquisas em Geociências, 38(2): 132-146.

Opolot, E. 2013. Application of remote sensing and geographical information systems in flood management: A Review. Research Journal of
Applied Sciences, Engineering and Technology, 6(10): 1884-1894.

Reboita, M., Gan, M., Rocha, R. \& Ambrizzi, T. 2010. Regimes de precipitação na América do Sul: uma revisão bibliográfica. Revista Brasileira de Agrometeorologia, 25(2): 185-204.

Rennó, C., Nobre, A.D., Cuartas, L.A., Soares, J.V., Hodnett, M.G. \& Tomasella, J., Waterloo, M. 2008. HAND, a new terrain descriptor using SRTM-DEM: Mapping terra-firme rainforest environments in Amazonia. Remote Sensing of Environment, 112: 3469-3481.

Righi, E. \& Robaina, L. 2010. Enchentes do Rio Uruguai no Rio Grande do Sul entre 1980 e 2005: uma análise geográfica. Sociedade \& Natureza, 22(1): 35-54.

Righi, E. \& Robaina, L. 2012. Risco à inundação no médio curso do Rio Uruguai: estudo de caso no município de São Borja - RS. Revista Brasileira de Geomorfologia, 13(3): 279-286.

Robaina, L., Trentin, R., Bazzan, T., Reckziegel, E., Verdum, R. \& Nardin, D. 2010. Compartimentação geomorfológica da bacia hidrográfica do Ibicuí, Rio Grande do Sul, Brasil: proposta de classificação. Revista Brasileira de Geomorfologia, 11(2): 11-23.

Rodrigues, G.O., Nobre, A.D., Silveira, A.C. \& Cuartas, L.A. 2011. Efeitos da resolução espacial de dados SRTM na descrição de terrenos obtida pelo modelo HAND (Height Above the Nearest Drainage) - estudo de caso em Manaus/AM. In: SIMPÓSIO BRASILEIRO DE SENSORIAMENTO REMOTO, 15, 2011, Curitiba. Anais... São José dos Campos, INPE, 2011, v. 1, p. 5769-5776.

Santos, J.S., Fontana, D.C., Silva, T.S.F. \& Rudorff, F.T. 2014. Identificação da dinâmica espaço-temporal para estimar área cultivada de soja a partir de imagens MODIS no Rio Grande do Sul. Revista Brasileira de Engenharia Agrícola e Ambiental, 18(1): 54-63.

Sanyal, J. \& Lu, X.X. 2004. Application of remote sensing in flood management with special reference to monsoon Asia: A Review. Natural Hazards, 33: 283-301.

Saueressig, S. S. 2012. Zoneamento das áreas de risco a inundação da área urbana de Itaqui, $R S$. Santa Maria, 101 p. Dissertação de Mestrado, Programa de Pós-graduação em Geografia e Geociências, Universidade Federal de Santa Maria.

Schumann, G. Bates, P., Horritt, M., Matgen, P. \& Pappenberger, F. 2009. Progress in integration of remote sensing-derived flood extent and stage data and hydraulic models. Reviews of Geophysics, 47: 1-20.

SEMA. Secretaria do Ambiente e Desenvolvimento 
Sustentável. 2014. Bacia hidrográfica do rio Ibicuí. Disponível em: <http://www.sema.rs.gov. br/>. Acesso em: 31 jul. 2014.

Silva, W.F., Molleri, G.S.F., Pinto, M.B.P. \& Araújo Junior, G.J.L.D. 2013. Análise do modelo HAND para a indicação de áreas suscetíveis a eventos críticos de cheias. In: SIMPÓSIO BRASILEIRO DE SENSORIAMENTO REMOTO, 16, 2013, Foz do Iguaçu. Anais... São José dos Campos, INPE, v. 1, p. 7011-7008

Soares-Filho, B., Rodrigues, H. \& Follador, M. 2013. A hybrid analytical-heuristic method for calibrating land-use change models. Environmental Modelling \& Software, 43: 80-87.

Townsend, P.A. 2001. Mapping seasonal flooding in forested wetlands using multi-temporal Radarsat SAR. Photogrammetric Engineering \& Remote Sensing, 67(7): 857-864.

UFSC. Universidade Federal de Santa Catarina. 2012. Atlas brasileiro de desastres naturais 1991

\section{Man 563}

Editores: Laurindo Guasselli \& Maria do Carmo Lima e Cunha. a 2010: volume Brasil. Florianópolis, CEPED, UFSC, $92 \mathrm{p}$.

Valeriano, M.M. \& Abdon, M.M. 2007. Aplicação de dados SRTM a estudos do Pantanal. Revista Brasileira de Cartografia, 59: 63-71.

Viana, D., Aquino, F.E. \& Matzenauer, R. 2006. Comportamento Espaço-Temporal da Precipitação no Rio Grande do Sul entre 1945-1974 e 19752004. In: CONGRESSO BRASILEIRO DE METEOROLOGIA, 14, 2006, Florianópolis. Anais... Florianópolis, SBMET, 2006, v. 1, p. 1-6.

Xaud, H.A.M., Bispo, P.C., Servello, E.L., Lima, A., Arenas-Toledo, J.M. \& Formaggio, A.R. 2009. Detecção de cicatrizes de queimadas a partir de imagens MODIS-TERRA no Estado do Mato Grosso. In: SIMPÓSIO BRASILEIRO DE SENSORIAMENTO REMOTO, 14, 2009, Natal. Anais... São José dos Campos, INPE, 2009. v. 1, p. 55235530. 
